2-1-2001

\title{
Harmonographs. II. Circular design
}

Robert J. Whitaker

Missouri State University

Follow this and additional works at: https://bearworks.missouristate.edu/articles-cnas

\section{Recommended Citation}

Whitaker, Robert J. "Harmonographs. II. circular design." American Journal of Physics 69, no. 2 (2001): 174-183.

This article or document was made available through BearWorks, the institutional repository of Missouri State University. The work contained in it may be protected by copyright and require permission of the copyright holder for reuse or redistribution.

For more information, please contact BearWorks@library.missouristate.edu. 


\section{Harmonographs. II. Circular design}

Robert J. Whitaker

Department of Physics, Astronomy, and Materials Science, Southwest Missouri State University, Springfield, Missouri 65804

(Received 3 February 2000; accepted 14 June 2000)

Devices that produce curves by the rotation of circles (or gears) about one another constitute one class of harmonographs. In the simplest case, a point on one of the circles will trace a cycloidal curve. A number of devices of varying degrees of complexity and which make use of gears or pulleys in their operation have been invented over the years to draw various curves. This paper offers a survey of some of these. (C) 2001 American Association of Physics Teachers.

[DOI: $10.1119 / 1.1309522]$

\section{INTRODUCTION}

A survey of various designs of pendulum apparatus that draw harmonic curves has been presented in the previous paper. These devices are often referred to as "harmonograms," and the curves they produce as "harmonographs." 1 Another class of such devices operates by the rotation of circles about one another. While the design of some of these is simple, others may be of considerable complexity. The basic mathematical concepts behind some of these instruments, however, are ancient-the attempt to describe the motion of the planets about a fixed earth.

The use of epicycles - circles moving on circles-is well known in the history of astronomy. A useful account is available in Dryer ${ }^{2}$ and an introductory explanation of its techniques is given by Crowe. ${ }^{3}$ An extensive study of these "cycloidal" curves was published by Proctor in 1878 in which he provided a detailed geometric explanation of the properties of a variety of such curves and also applied these ideas to selected astronomical problems. ${ }^{4}$ Proctor's book is also illustrated by a number of diagrams which were mechanically drawn.

While beyond the scope of this paper, mechanical devices, which employed gears in clocks and various astronomical devices, must be mentioned. Among the latter are various planetaria and orreries which display the relative motions of the earth and moon about the sun or the planets about the sun. With these the observer views the moving object, and there is no attempt to provide a permanent record of this motion on paper. A detailed, illustrated history of these devices is given by King and Millburn. ${ }^{5}$

Another device, specifically designed to produce a permanent record of the motion of a "curve moving on a curve," was the "geometric chuck." These were devices attached to a lathe for cutting decorative patterns in wood or metal. Among the references to early ones are those of Suardi around 1750 and of Ibbetson around $1833 .{ }^{6}$ Bazley provided an extensive discussion of the use of Ibbetson's chuck in 1875 along with a comprehensive set of examples of the curves that could be drawn with it. ${ }^{7}$ He noted the importance of such apparatus to have an attachment for a pencil or pen so the curves could be traced on paper before it is used for its intended purpose. The diagrams reproduced in his book were so prepared. ${ }^{8}$

\section{CIRCULAR HARMONOGRAPHS}

Over the years a number of devices have been developed with the specific purpose of drawing curves. Of the class under consideration here are those that use wheels in their operation. These may be gears that mesh with other gears or wheels that may be connected to one another by means of some kind of belt. One advantage of apparatus of this type over pendulum apparatus is the absence of damping that is present with the pendulums. If the wheel apparatus completes a closed curve, it will trace exactly the same path again. Thus, one may set the apparatus to draw a particular curve and be sure that one will get the same curve each time.

One such apparatus was described in 1869 by Edward Pickering. Describing the experiment of Lissajous and the curves produced from two vibrating tuning forks, he noted the value of having a set of curves drawn for comparison. He then described a machine, which he had devised, for drawing the same curves mechanically. "The paper on which the curves are drawn receives a horizontal motion to and fro, while, at the same time, the pen is moving vertically up and down." 9 This is shown in Fig. 1.

$\mathrm{A}$ [rthur] $\mathrm{E}$ [dward] Donkin described an apparatus of his design that drew the curve resulting from the superposition of two sine curves (Fig. 2). This apparatus employed several gears that could be turned by a crank. A strip of paper, for recording the curve, moves between a set of rollers in one direction, and the frame along which the paper moves also moves at right angles to the motion of the paper and with the

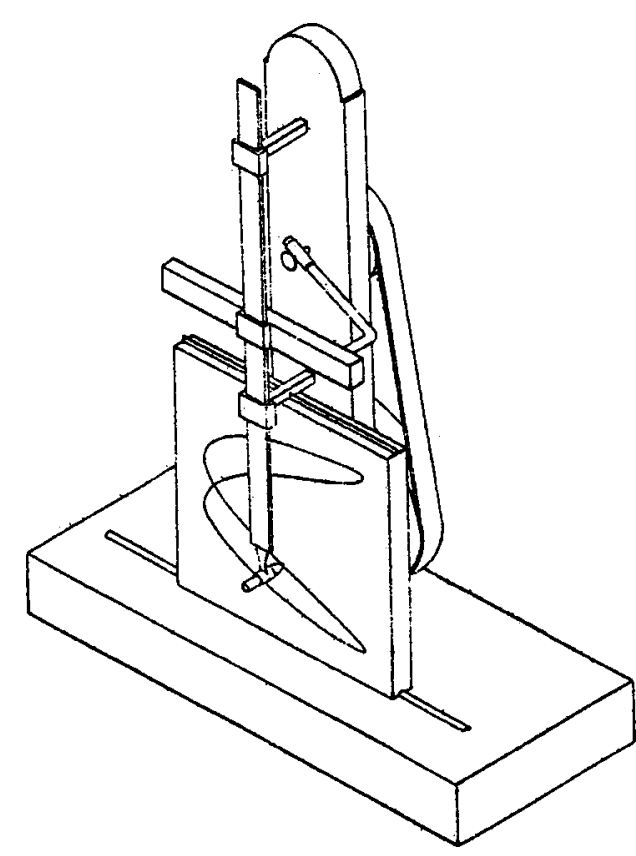

Fig. 1. Pickering's mechanical "Lissajous" apparatus. 


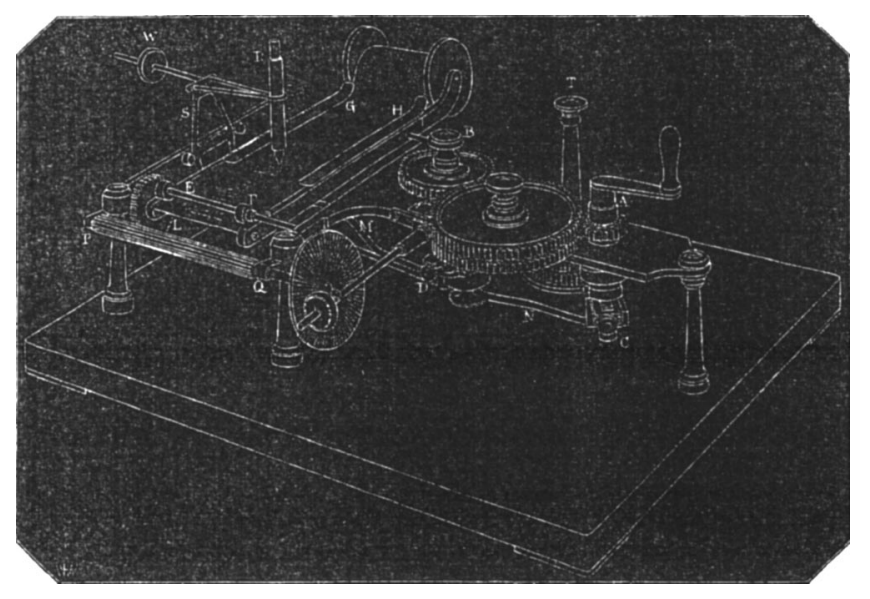

Fig. 2. Donkin's harmonic curve apparatus.

harmonic motion imparted to it by the gears operating the apparatus. A fixed pencil then records the motion imparted to the paper. ${ }^{10}$

At a meeting of the Physical Society on 24 May 1879 W. J. Wilson “.... exhibited a new harmonograph and figures drawn by it.... In this instrument toothed wheels take the place of pendulums, the ratio of the teeth giving the ratio of the periods of the motions." 11 The author provided no diagram of his apparatus, and I have found no subsequent description of it. It is also not clear from this brief account what kind of curves it traces. However, this paper is cited in The Oxford English Dictionary as a source of the term, "'harmonograph.," 12

The "cycloidotrope" is described by Hopkins, and his illustration is shown in Fig. 3. He attributed its invention to A. Pumphery, of Birmingham, England. ${ }^{13,14}$ The middle of the apparatus contains a smoked glass plate upon which the curve may be traced. The plate is held in the middle of a ring by the two springs, one shown at the top and the other at the bottom of the ring.

The face of the ring has a toothed rim, which is engaged by a small pinion on the crank shaft, and the periphery of the ring is provided with 202 spur teeth, which engage a pinion having 33 teeth and turning on a stud projecting from the base plate [to the left of the ring].

An adjustable rod is attached to the spur pinion; one end is attached to a pin which holds the tracing pen fastened with a thumb screw. A steel tracing point, held in place with a curved spring, is attached to one end of the tracing pen over the glass plate. The other end of the pen is held by a movable arm that may pivot about a pin set in the base plate. ${ }^{15}$ Some of the curves that may be drawn with the cycloidotrope are

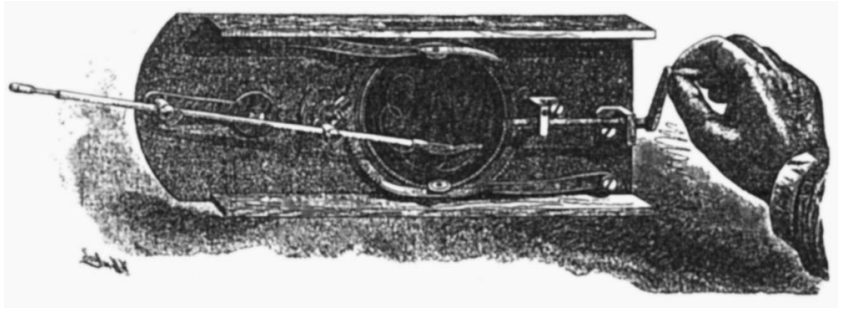

Fig. 3. Pumphery's "cycloidotrope."

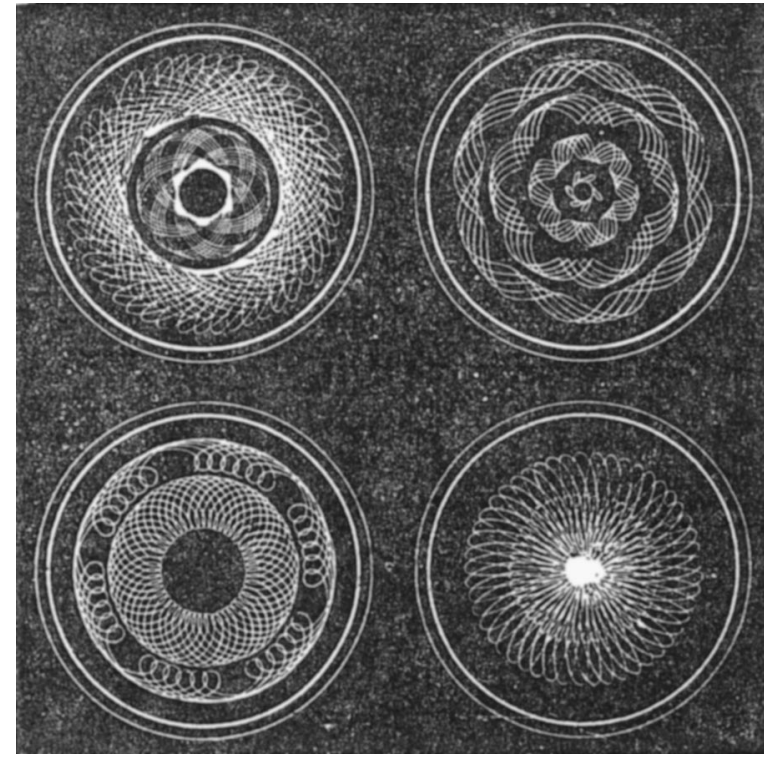

Fig. 4. Curves drawn with the cycloidotrope.

shown in Fig. 4. It should be noted that each of these diagrams is made up of tracings of several separate settings of the apparatus traced on the same plate.

The most elaborate apparatus, to date, was the "campylograph' designed by Marc Dechevrens. (The name comes from the Greek, "curves"' and "I write or draw."') He described the curves it could draw in three articles (Refs. 16, 17, and 18). Further discussion of his device, with illustrations, was published in La Nature ${ }^{19}$ and a second article, based on this one, was published in Scientific American Supplement. ${ }^{20}$ A picture of his apparatus (printed in each of the above) is given in Fig. 5.

William F. Rigge, who had carried on extensive correspondence with Dechevrens, also provided a discussion of Dechevrens' apparatus and the curves it could produce. Four

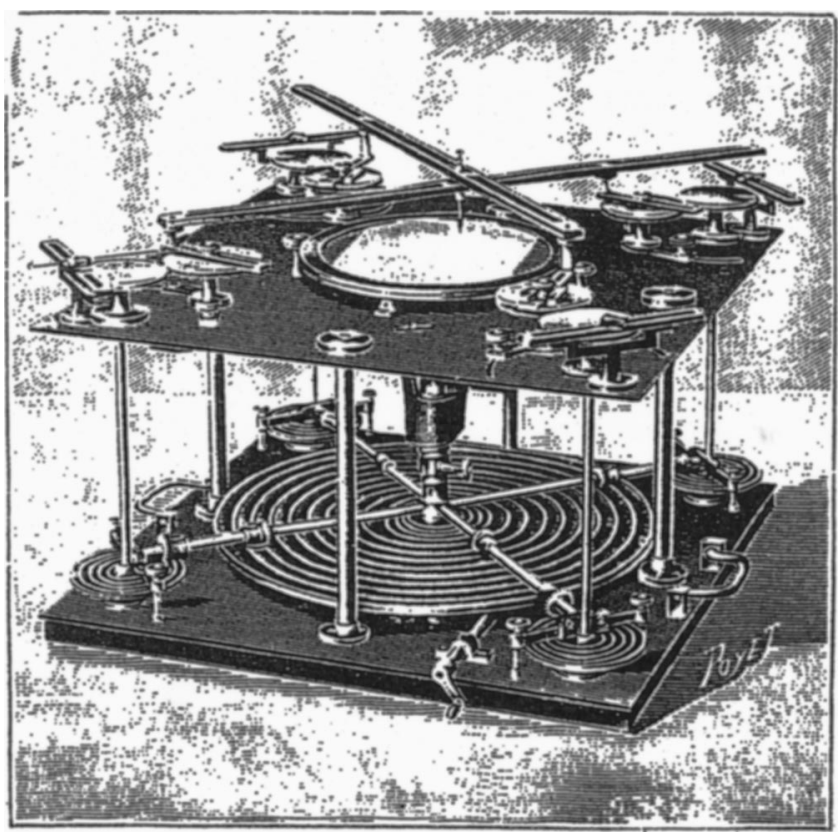

Fig. 5. Dechevrens's "campylograph." 


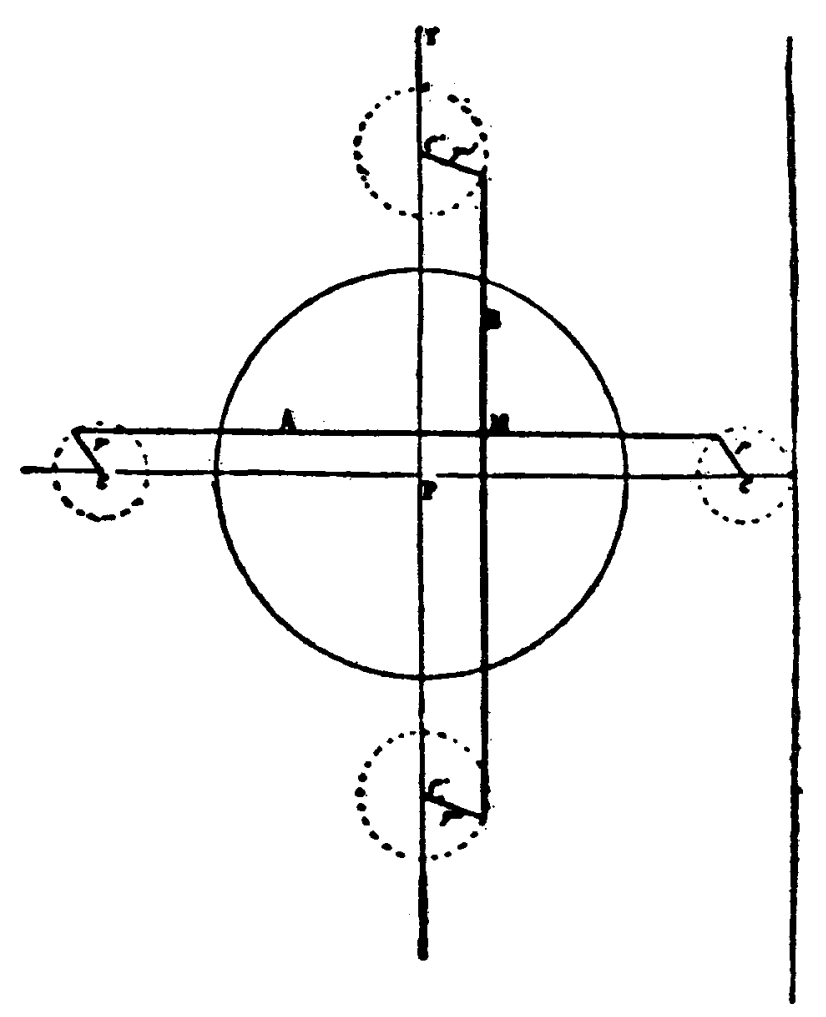

Fig. 6. Diagram of the campylograph.

small wheels are located at each corner of a square plate. One end of a crank pin is free to rotate about a point in one wheel; the other end of the pin is attached to a short rod. The other end of the rod rotates about a second pin which is free to pivot about a point in a long rectangular bar. An identical system joins the other end of the long bar to the wheel diagonal to the first. A second long bar is similarly attached to the other two diagonal wheels. A pen is mounted at the intersection of the two bars. Finally, paper is fastened to a disk that may be made to rotate under the pen (see Fig. 5). Directly below each of the four small wheels and the center disk is a system of interconnected gears which may be turned, simultaneously, by a crank. The two bars, each and separately, may then be given transverse and rotational motion as each wheel turns; and the disk with the paper may also be rotated. The gears can be replaced with gears of other sizes to increase the variety of curves that could be drawn. Rigge noted that there were 979 possible combinations that could be introduced. ${ }^{21}$ A line diagram of the apparatus is given in Fig. $6 .^{22}$

Rigge mentioned that Dechevrens had built a second, improved design of the campylograph. However, the pictures and the brief description he provided are insufficient to determine its operation. Dechevrens had informed Rigge that he had completed an elaborate, illustrated account of the campylograph ready for the printer. But, Rigge observed, with Dechevrens' death in 1923, the work would probably never be published. ${ }^{23}$

In 1916 Robert Moritz, a mathematician at the University of Washington, reported on an instrument of his design which he called the "cyclo-harmonograph." The choice of this term, he explained, is because the operation of this instrument produced a curve that was " $\ldots$ the locus of a point

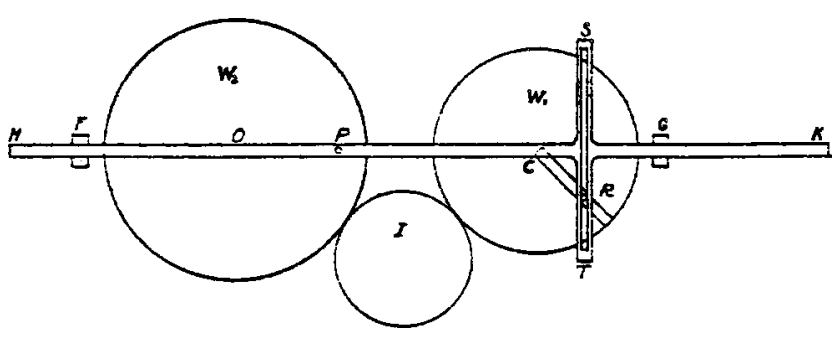

Fig. 7. Moritz's "cyclo-harmonograph."

which has simple harmonic motion in a straight line while at the same time this line rotates uniformly about one of its points.", 24

A simplified diagram of his apparatus is shown in Fig. $7 .^{25}$ As Moritz described its operation:

A wheel $W_{1}$, center $C$, carries a crank-pin $R$ which, as the wheel rotates, slides in a slotted crossbar $S T$ of a cross-head $H K$ perpendicular to $S T$. This cross-head is constrained to move in the direction of $H K$ by means of two fixed guides $F$ and $G$. As the wheel $W_{1}$ moves with constant angular velocity about its center $C$, any point $P$ in $H K$ will have simple harmonic motion in the direction of $H K$.

Let now the mechanism thus far described be made to revolve about a fixed wheel $W_{2}$, center $O$, by means of an idle-wheel $I$ which connects the circumferences of the wheels $W_{1}$ and $W_{2}$. Any point $P$ in $H K$ will then receive rotary harmonic motion and a pencil or pen-point placed at $P$ will trace out a cyclic-harmonic curve in the plane of the paper. ${ }^{26}$

The author noted that the locus of $P$, then, was independent of the distance between the centers of the two wheels; it depended only on the dimensions of the two wheels; it depended on the distance of the crank-pin $R$ from the center, $C$, of $W_{1}$; and it depended on the, arbitrary, initial position of $P$ and $R$. The curve produced will be the same if wheel $W_{2}$ is fixed and $W_{1}$ revolves around it or if the centers of both wheels are fixed, and allowed to revolve, and the paper on which the curve is traced is fastened to wheel $W_{2}$. The latter arrangement, he observed, is more advantageous. ${ }^{27}$ The apparatus was so designed that a set of ten wheels of different radii ( $W_{1}$ and/or $W_{2}$ ) could be raised or lowered to the plane of the idle wheel with which it meshes, thus allowing easy adjustment of which wheel(s) would be used in drawing the desired curve. ${ }^{28}$

The polar equation for the locus of point $P$ may be shown to be

$$
\rho=a \cos [(p / q) \theta]+k,
$$

where $\rho$ and $\theta$ are the polar coordinates of point $P$ from point $O ; a$ is the distance $C R$; and $k$ is the distance of any point $P_{0}$ on $H_{0} K_{0}$ from $O_{0} ; p$ and $q$ are the radii of the wheels $W_{2}$ and $W_{1}$, respectively. ${ }^{29}$ As has been noted, the instrument behaves as if wheel $W_{2}$ is fixed and wheel $W_{1}$ rotates around it. This being the case, the point $P$ will trace that curve known as an "epitrochoid." This class of curves will be discussed more completely in the Appendix. 


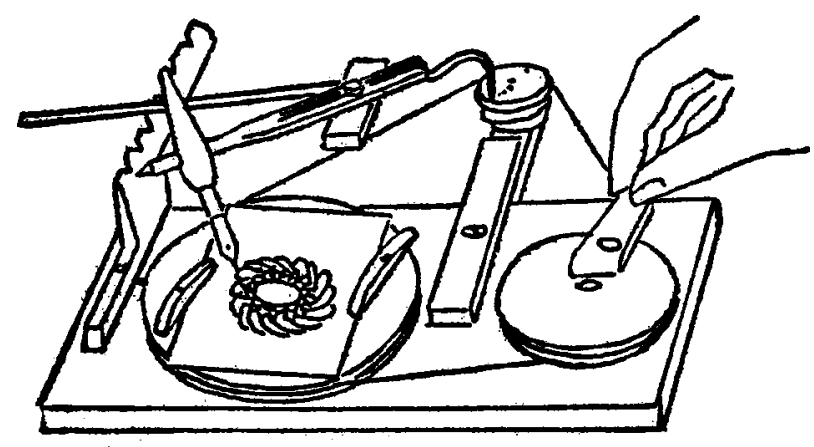

Fig. 8. The "wondergraph."

Banfield, in introducing his "photo-ratiograph" in 1921, had the following to say about harmonographs:

The harmonograph, generally speaking, is somewhat tolerantly regarded in physical circles as a scientific toy, though the beauty of the result never fails to excite admiration, grudging though it may be. The cause of this attitude probably lies in the fact that science always deals with exact premises, and in this the usual pendulum-controlled harmonograph fails lamentably. ${ }^{30}$

His design, he noted, eliminated the lack of precision that he had found with pendulum apparatus. It operated with a series of gears and a mechanical linkage, which he described as " ... a kind of inverted pantagraph." Instead of a pen to record the path of the curve, a brightly illuminated pin-hole was recorded on a photographic plate when the apparatus and camera were placed in a darkened room. The description and photographs of the apparatus were insufficient to determine its exact method of operation. ${ }^{31}$ The caption of a photograph, showing this apparatus on display in the Science Museum in London, provides an interesting contrast to the designer's comments above:

The beauty of mathematical figures such as these provided evidence for those who argued that mathematics did not exile beauty from the world. No conflict need exist between the admirers of the natural forms and the partisans of mathematics and mathematical methods. ${ }^{32}$

The various apparatus described above suggests a degree of complexity that could preclude its reproduction by an amateur in mechanical crafts, even if sufficiently detailed descriptions were provided. However, designs of apparatus for someone to construct with basic hand tools have been described. One of these is the "wondergraph," described by Collins and shown in Fig. 8. Details for construction are provided by the author. ${ }^{33}$ A nearly identical apparatus was also described by Stong, after a design by Tom Barnard. ${ }^{34} \mathrm{~A}$ comparison of each of these with the "campylograph" reveals a strong similarity in basic design.

Another device, that operates almost identically to those in the previous paragraph, is the "schemagraph" described by Bulman. While its construction is somewhat more sophisticated and requires a greater skill with tools, the author has provided detailed notes for its construction. ${ }^{35}$

One of the simplest and, in many ways, the most versatile devices described in the literature is Hoferer's "kukulograph." The author noted that the name means "circle-

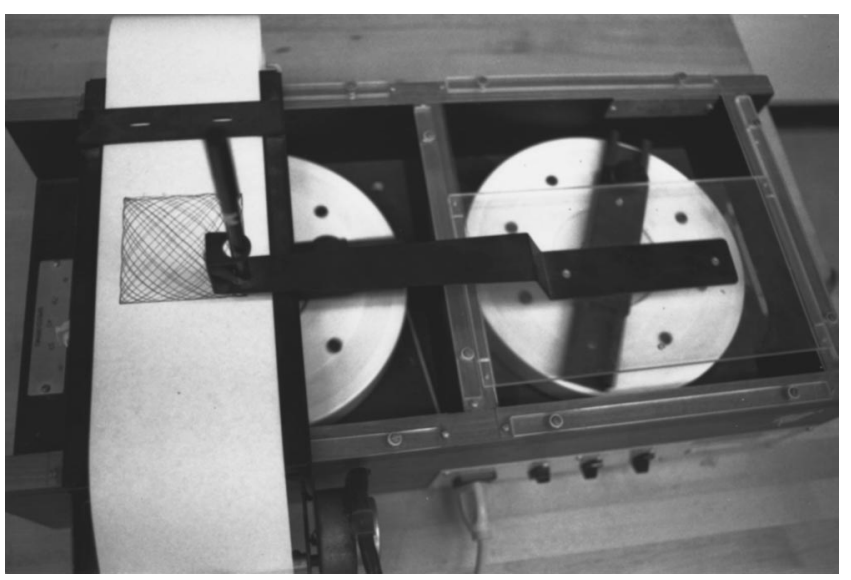

Fig. 9. Turntable oscillators drawing a curve.

circle-writer." Two or more annular rings are cut from a piece of $\frac{1}{2}$-in. fiber board. Several disks of different radii are similarly cut, and holes are drilled in the disks at various distances from the center. The ring is held firmly, and a disk may be rotated around the outside or around the inside of the ring; a pencil placed in one of the holes in the disk will trace its path. The curve produced depends on the relative radii of the disk, of the ring, and on the position of the hole in the disk. ${ }^{36}$ A working design could also be constructed from heavy cardboard without too much difficulty.

One may recognize this apparatus as being identical in concept and basic design to the popular toy, "Spirograph ${ }^{\circledR}$,", which appeared on the market in $1967 .{ }^{37}$ The problem of possible slippage between the ring and the disk of the kukulograph is eliminated by the toothed gears of which the Spirograph is made. This writer has provided a detailed discussion of the curves possible with this device elsewhere. ${ }^{38}$ The results are summarized in the Appendix.

A pair of turntable oscillators-using phonograph turntables-were employed by Project Physics to demonstrate harmonic motion and the superposition of two harmonic motions. A Plexiglas ${ }^{\mathrm{TM}}$ platform was attached to the turntable by means of a pin; the platform then moved in one direction between guides as the turntable rotated, executing simple harmonic motion. A second platform, which held the paper, was moved similarly by a second turntable and perpendicular to the first. Figure 9 shows the apparatus drawing a curve. While there were four different speeds that could be changed for each of the turntables $\left(16 \frac{2}{3}, 33 \frac{1}{3}, 45\right.$, and $\left.78 \mathrm{rpm}\right)$, neither could be "fine" adjusted. Similarly, lack of complete smoothness of the platforms between the guides affected the quality of the figure produced. ${ }^{39}$

In addition to the above one finds mention or brief descriptions of a variety of devices for producing and/or recording some form of repetitive motion. Mach, for example, briefly described an apparatus of his design to illustrate the superposition of three harmonic curves or to produce "Lissajous' curves." ${ }^{40}$ Pictures and cursory descriptions of several mechanical devices for producing simple harmonic motion have also been published by Frick ${ }^{41}$ and by Miller. ${ }^{42}$

A diagram of an interesting apparatus by Stöhrer is given in Fig. 10. Each of the disks executes simple harmonic motion in its plane of motion. A small beam of light passes through the point of overlap between the two disks, and the mutually perpendicular motion of the two disks allows the 


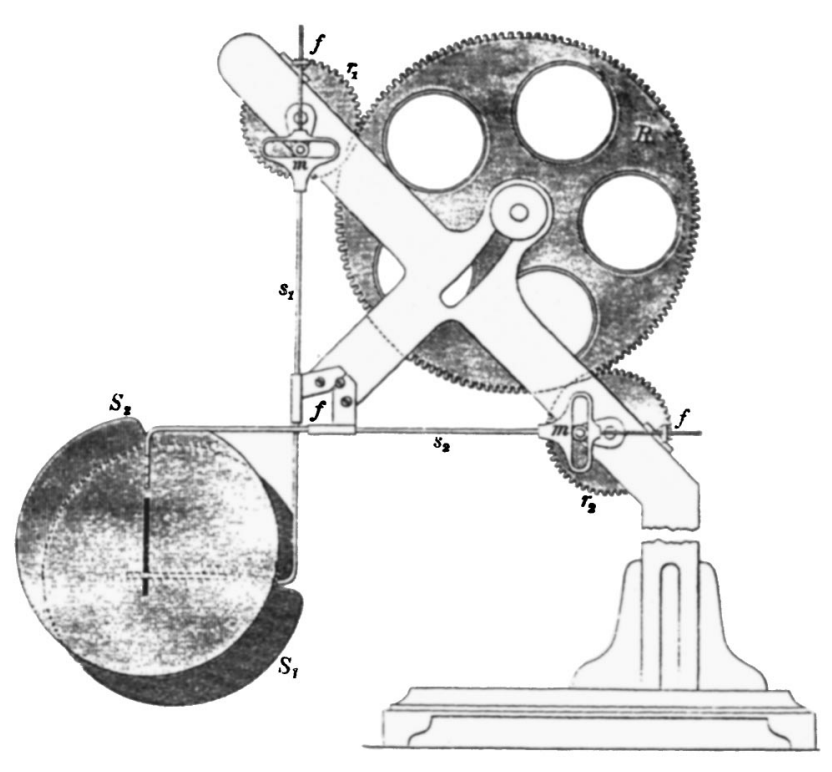

Fig. 10. Diagram of Stöhrer's apparatus.

light to trace a Lissajous figure on a screen. Greenslade has described this apparatus and has published a photograph of the one in the Smithsonian collection. ${ }^{43}$ While some of the apparatus described above make limited use of mechanical linkages, no attempt has been made to survey this potential class of devices. ${ }^{44}$

\section{THE CREIGHTON COMPOUND HARMONIC MOTION MACHINE}

Of the many devices invented to trace curves based on some form of repetitive motion, none is more detailed or more complex than the "Creighton Machine" constructed by William F. Rigge, S. J. at Creighton University and shown in Fig. 11. Rigge noted that he had begun work on it in January 1915 and had completed it in its final form in May 1924. ${ }^{45}$ The machine was capable of drawing both "rectangular', curves ("Lissajous"' curves) and cycloidal curves; indeed, it could reproduce any curve that was possible with any of the other devices previously described. He noted that basic to its design was mathematical accuracy. Thus one could set the machine to draw any desired curve, based on its equation. Prior to the completion of his machine several articles were published that described its function. ${ }^{46}$

The machine was constructed with an arrangement of pulleys and gears such that various gear ratios could easily be changed. In addition an attachment could be moved with simultaneous simple harmonic motion in two directions perpendicular to one another for drawing rectangular curves. Other types of curves could be drawn on a rotating table or on a moving ribbon, the motion of either (and of the pen) being determined by the setting of the various gears. The machine was driven by a motor, and a single curve could take several minutes to draw; in its most complex setting Rigge calculated that it could take more than two years to complete a curve. In all, he determined that more than 7.6 billion different curves could be drawn with his machine. ${ }^{47}$

\section{DISCUSSION AND CONCLUSIONS}

The author of the obituary of Professor Hugh Blackburn in the Times (London) observed that Blackburn

... had invented and exhibited in his rooms in Cambridge a pendulum with a double suspension, which in subsequent years became known as the Blackburn pendulum, and by the use of which important advances were made in experimental physics. ${ }^{48}$

While one may still wonder about details of the "important advances,' a number of different pendulum devices designed for drawing curves have been invented over the years, and these have been traced in a previous paper. Those apparatus which make use of gears and pulleys to draw other classes of curves have been examined in this paper.

Rigge observed that both pendulum and wheel harmonographs had advantages and disadvantages. Among the advantages of pendulum devices were: their cheapness; the beauty of the curves produced as the amplitude of each pendulum decreased; and the possible adjustment of the angles between the pendulums. Disadvantages, he noted, were: restriction to rectangular curves; time required to "finish" a curve; trial and error in determining the curve to be drawn; and decreasing amplitude of pendulums.

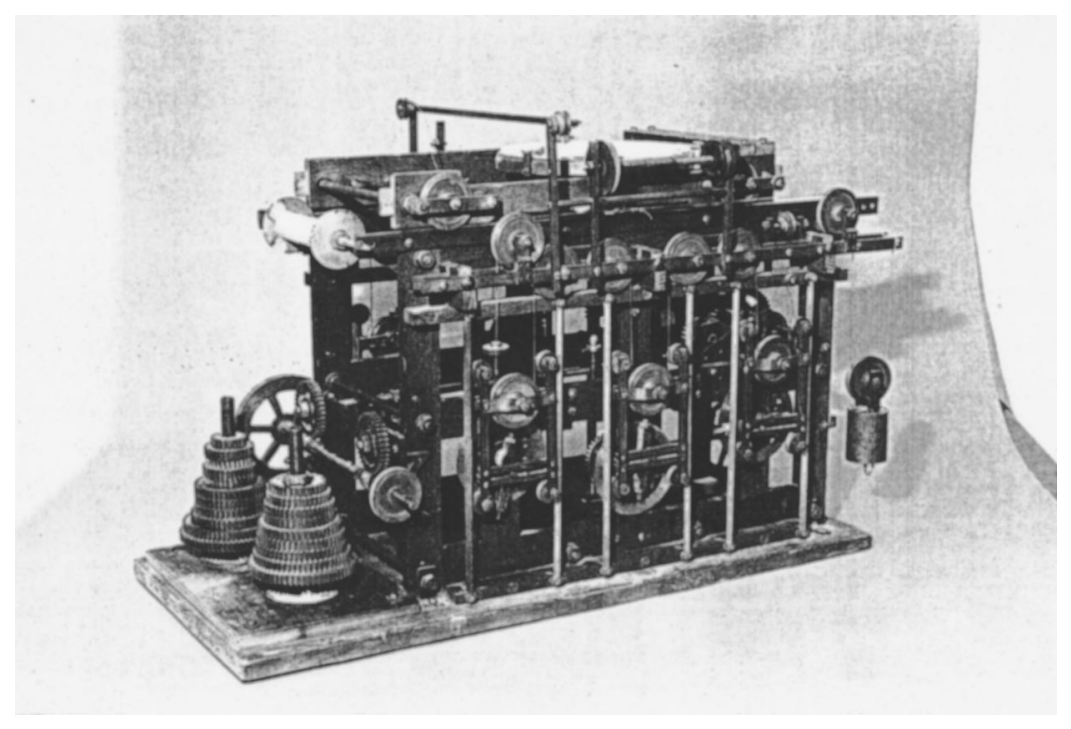

Fig. 11. Fr. Rigge's "Creighton Machine." 
The advantages of wheel machines were that all variables might be determined and set in advance; they could be stopped and restarted without affecting the curve; they could be designed to draw any type of curve; and they could be built to be very rugged. Disadvantages were: cost; limited class of curves that could be drawn with simple machines; need for mechanical skill in construction; imperfections in construction; and possible complexity of the machine. ${ }^{49}$

It would seem that harmonographs of either kind were developed primarily as demonstration apparatus. While the pendulum apparatus could demonstrate simple harmonic motion in mutually perpendicular directions and record the curves produced, the production of a variety of curves was often the primary purpose for building the apparatus. And, the curves were produced because of their aesthetic characteristics.

Rigge noted, in the first paragraph of the Preface to his book, that

Harmonic curves always captivate the eye by their wonderful beauty and their endless variety. They have that correct proportion in their apparent complexities which allures the draughtsman, and that fecundity in mathematics which attracts the beginner and holds the veteran. ${ }^{50}$

And, while much of his book is devoted to the mathematical and mechanical means of curve production, a full chapter is devoted to their beauty. ${ }^{51}$

More recently, Cundy and Rollett observed in their book, Mathematical Models, that

The harmonograph was a popular diversion in Victorian drawing-rooms, since when it has suffered a decline and is rarely seen today. The construction of a good machine entails a considerable amount of labour and skill, but the effort will be well repaid, and it makes a fascinating contribution to any mathematical exhibition that may be planned. ${ }^{52}$

While the harmonograph may have been popular in Victorian times, its attraction has extended to the present time. That interest in harmonographs has not been lost is clear from the recent publications on the subject by Greenslade. ${ }^{53}$ The curves - symmetric and nonsymmetric — drawn by these devices seem to provide a particular fascination to many people. This fascination extends beyond the usefulness of the curves in describing some physical phenomena, but also includes an appreciation of the beauty of the curves. The recent interest in the variety of fractal forms is one example of this. Complex curves, with a great deal of detail, may be produced with a small computer and can be observed on the monitor; but, as Tolansky remarked, these cannot compare in interest with those produced by a "crude" mechanical device that traces the curve on paper as we watch it grow. ${ }^{54}$

Harmonographs are only one of many classes of demonstration equipment that have been designed for use in physics lectures or laboratories that no longer see active use. However, as some of the writers cited above have noted, these " "antique', devices may still serve a purpose in bringing one piece of physics (or mathematics) to students or the general public. Do departments (and their institutions) which have old apparatus have a responsibility for their preservation and possible display? To what extent do faculty (much less our students) have an understanding or appreciation of this aspect of the intellectual heritage of our discipline?

Collecting antique scientific instruments has also become an active hobby. Many items bring high prices at auctions. ${ }^{55}$ As departments search for space for new equipment by disposing of older, unused items, it might be wise to identify these before they are discarded.

These two papers have attempted to survey the development of harmonographs through published accounts of various designs. These have been found in publications directed toward the professional as well as the general reader. The author is aware that many harmonographs are on display in museums and in some physics departments, but he has made no attempt to survey these. It is his hope that the history of these devices may encourage others to explore the dusty corners of the "philosophical cabinets" of their college and university departments and to consider the range of curves that can be produced and displayed through the varied design and operation of these early "analog computers."

\section{ACKNOWLEDGMENTS}

The author is indebted to the staff of the Interlibrary Loan Department of the Duane G. Meyer Library for their diligent efforts in obtaining many of the references used in the preparation of this article. The picture of the "Creighton Machine", was taken by Robert U. Guthrie and provided by the Creighton University Public Relations Department. He also extends his appreciation to the Graduate College and the Faculty Leave Committee of Southwest Missouri State University for the grant of a Summer Faculty Fellowship to provide the time for the writing of this paper. Thomas B. Greenslade, Jr. provided a number of valuable suggestions to an earlier draft of this paper. I have attempted to acknowledge these where they occur.

\section{APPENDIX: CYCLOIDAL CURVES}

Many curves are defined kinematically. That is, something moves, under some kind of constraint, with respect to something else. For example: "The circle is usually defined as the locus of a point $P$ such that the distance from $P$ to a fixed point $O$ is constant." 56 All of the curves drawn by the various apparatus discussed above operate in this manner. The curve produced is the locus of a point defined by the motion of that part of the apparatus that carries the recording device.

For the case of curves rolling on curves, Lockwood provides the following definitions:

If a curve rolls, without slipping, along another, fixed curve, any point or line which moves with the rolling curve describes a roulette. ${ }^{57}$

The term trochoid has the same meaning as roulette. It is used more particularly for the roulettes traced by points carried by a circle rolling on a fixed circle. These are called epitrochoids or hypotrochoids according as the circle rolls on the outside or inside of the fixed circle. ${ }^{58}$

However, if the tracing point is on the circumference of the rolling circle, the roulette traced is called an epicycloid or hypocycloid ${ }^{59}$ Clearly, any curve drawn with the "kukulograph" or the Spirograph will be an epitrochoid or a hypotrochoid; a "pure", epicycloid or hypocycloid would not be possible because of the interference of the gear teeth with the pen or pencil drawing the curve. ${ }^{60}$

Figure 12 illustrates the geometry of the epitrochoid, in which circle $M$ rotates around the outside of the fixed circle, 


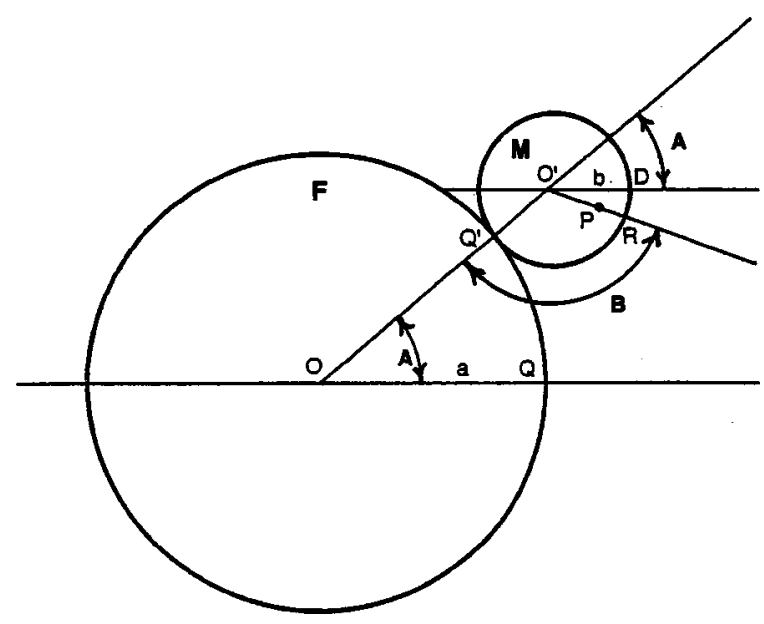

Fig. 12. Geometry of the epitrochoid.

$F$. The radius of the fixed circle is $a$; the radius of the rotating circle is $b ; h$ is the distance of the tracing point, $P$, from the center of $M$. The parametric equations of the coordinates of the recording point are

$$
x=(a+b) \cos A-h \cos \{[(a+b) / b] A\}
$$

and

$$
y=(a+b) \sin A-h \sin \{[(a+b) / b] A\} .
$$

The geometry of the hypotrochoid is illustrated in Fig. 13, where the circle, $M$, rotates around the inside of the fixed circle. The parametric equations of the coordinates are

$$
x=(a-b) \cos A+h \cos \{[(a-b) / b] A\}
$$

and

$$
y=(a-b) \sin A-h \sin \{[(a-b) / b] A\} .
$$

In the case of the Spirograph, each gear (or ring) has an integral number of teeth. Thus the rolling gear must roll through $n$ complete circles to return to its starting position while it rolls around the fixed circle in $m$ complete circles. Since the number of teeth of each gear is proportional to its respective radius, we may write their ratios as

$$
m / n=a / b .
$$

If we make this substitution for " $a$ " in each of the four equations above, we obtain, for the epitrochoid:

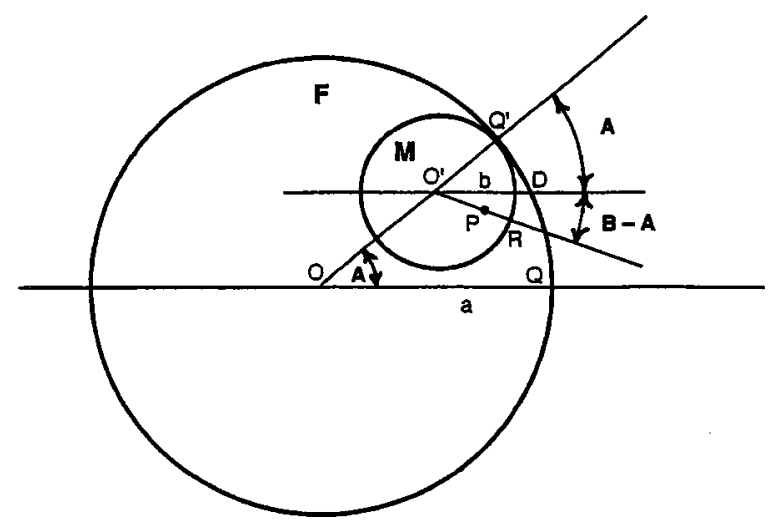

Fig. 13. Geometry of the hypotrochoid.
Table I. Cases of special trochoids.

\begin{tabular}{lll}
\hline \hline Condition & Gear ratio $(m / n)$ & \multicolumn{1}{c}{ Name of curve } \\
\hline $\begin{array}{l}\text { Epitrochoids } \\
\text { A. } a=b\end{array}$ & 1 & Lamaçon \\
B. $a=0$ or & 0 & Circle \\
$\quad h=0$ & Any & Epicycloid \\
C. $h=b$ & Any & 1. Cardioid \\
1. $a=b$ & 1 & 2. Nephroid \\
2. $a=2 b$ & 2 & \\
Hypotrochoids & & Ellipse \\
A. $a=2 b$ & 2 & Hypocycloid \\
B. $h=b$ & Any & 1. Circle with radius $a$ \\
1. $b=0$ & Any & 2. Point \\
2. $a=b$ & 1 & 3. Line segment (special case \\
3. $a=2 b$ & 2 & of A) \\
4. $a=3 b$ & 3 & 4. Deltoid \\
5. $a=4 b$ & 4 & 5. Astroid \\
\hline \hline
\end{tabular}

$$
x=b[(m / n)+1] \cos A-h \cos \{[(m / n)+1] A\}
$$

and

$$
y=b[(m / n)+1] \sin A-h \sin \{[(m / n)+1] A\} .
$$

And the equations for the hypotrochoid are

$$
x=b[(m / n)-1] \cos A+h \cos \{[(m / n)-1] A\}
$$

and

$$
y=b[(m / n)-1] \sin A-h \sin \{[(m / n)-1] A\} .
$$

A number of interesting curves result from particular relationships between the radii of the circles (or of the gear ratios). These curves may be obtained from each of these pairs of equations with the proper substitution. Some of these are summarized in Table I.

${ }^{1}$ Robert J. Whitaker, “Harmonographs. I. Pendulum design,” Am. J. Phys. 69, 162-173 (2001)

${ }^{2}$ J. L. E. Dryer, A History of Astronomy from Thales to Kepler (Dover, New York, 1953), 2nd ed., pp. 151-170; 191-206.

${ }^{3}$ Michael J. Crowe, Theories of the World from Antiquity to the Copernican Revolution (Dover, New York, 1990), pp. 20-52.

${ }^{4}$ Richard A. Proctor, A Treatise on the Cycloid and all Forms of Cycloidal Curves (Longmans, Green, London, 1878).

${ }^{5}$ Henry C. King and John R. Millburn, Geared to the Stars: The Evolution of Planetariums, Orreries, and Astronomical Clocks (University of Toronto Press, Toronto, 1978). An illustrated account of some of these may also be found in Harriet Wynter and Anthony Turner, Scientific Instruments (Scribner's, New York, 1975), pp. 7-52. Simplified approaches to demonstrating retrograde motion have recently been described in Francis S. Lestingi, "Projection epicycles," Phys. Teach. 11, 249 (1973); Albert Ackroyd and Hendrik J. Gerritsen, "A retrograde motion demonstration model," Am. J. Phys. 54, 1021-1023 (1986); Matthew J. Moelter and Bernard A Bates, “'Hands-on' epicycles and retrograde motion,"' Phys. Teach. 35, 554-556 (December, 1997).

${ }^{6}$ Giovani Battista Suardi, Nuovi Instromenti per la Descrizione di Diverse Curve Antiche... (G.-M. Rizzardi, Brescia, 1752). See National Union Catalog Pre-1965 Imprints (Mansell, Chicago, 1978), Vol. 575, p. 193. John Holt Ibbetson, A Brief Account of Ibbetson's Geometric Chuck, Manufactured by Holzapffel \& Co. (By the author, London, 1833). Ibbetson wrote several books on "circular turning." See National Union Catalog Pre-1965 Imprints (Mansell, Chicago, 1973), Vol. 263, p. 110. I have not seen either reference. Proctor (Ref. 4, p. 194) refers to both of these in a long quote about the "geometric chuck" written by Henry Perigal, who had constructed a similar device by means of which several of the illustrations were made for Proctor's book. L. W. Boord also drew several illustrations for this book using a device similar to Perigal's. Drach had 
referred to Perigal some years before. He wrote of curves shown in a demonstration “ “... by Mr. Perigal at Lord Northampton's scientific soirée in March 1846. The Royal Society, Astronomical Society and Royal Institution, possess three volumes of various singular epicyclical curves executed by Mr. Perigal's machinery, some of which are highly ornamental,... .' S. M. Drach, “An easy rule for formulizing all epicyclical curves with one moving circle by the binomial theorem,' Philos. Mag. J. Sci. Third Series 34, 444-448 (June, 1849); the quotation appears on p. 448. De Morgan referred to diagrams of trochoidal curves that had been drawn by Perigal for the Penny Cyclopaedia; he also noted that Northampton (Spencer Joshua Alwyne Compton, second Marquis of Northampton) was president of the Royal Society from 1838 to 1849 . Augustus De Morgan, A Budget of Paradoxes, edited by David Eugene Smith (Open Court, Chicago, 1915; Books for Libraries Press, Freeport, NY, 1969), Vol. 2, 2nd ed., pp. 19-20. A brief obituary of Perigal may be found in "Obituary: Mr. Henry Perigal,' The Times (London), 9 June 1898, p. 6. In spite of these references to Perigal's "machine", I have been unable to find further description of it. Proctor also referred to Perigal's invention of ".. an ingenious instrument, called the kinescope (sold by Messrs. R. \& J. Beck, of Cornhill), by which all forms of epicyclics can be ocularly illustrated. A bright bead is set revolving with great rapidity about a centre, itself revolving rapidly about a fixed centre,... and thus any epicyclic traced out. The motions are so rapid that, owing to the persistence of luminous images on the retina, the whole curve is visible as if formed of bright wire." Reference 4, pp. 194-195. This description is virtually identical to an apparatus attributed to Charles Wheatstone and described (and illustrated) by Ganot who called it "Wheatstone's photometer." Elementary Treatise on Physics, Experimental and Applied, translated and edited from Ganot's Éléments de Physique by E. Atkinson (William Wood, New York, 1899), 15 th ed., p. 516. Its description is sufficiently different from the one described by Wheatstone on 8 March 1833 before the Royal Institution, which also made use of luminous points carried by a wheel moved by a train of gears. See The Athenæum, 170-171 (16 March 1833). Wade noted that this 1833 experiment had not seemed to have been published, nor does he mention the "photometer." Nicholas J. Wade, Brewster and Wheatstone on Vision (Academic, London and New York, 1983), p. 313. Frick described the "reflection photometer"' (Reflexphotometer), a nearly identical apparatus, which he attributed to Wollaston. See Joseph Frick, Dr. J. Fricks Physikalische Technik;..., Zweiter Band, Zweite Abteilung (Friedrich Bieweg und Sohn, Braunschweig, 1909), 7th ed., p. 1759. I have been unable to find original references to either of these devices. Wheatstone's interest in acoustical phenomenon also led to his construction of machines to demonstrate wave motion. A discussion of this appears in Howard A. L. Dawes, "Wheatstone's wave machine: A physical model of light," in Making Instruments Count: Essays on Historical Scientific Instruments presented to Gerard L'Estrange Turner, edited by R. G. W. Anderson, J. A. Bennett, and W. F. Ryan (Variorum, Aldershot, Hampshire, UK and Brookfield, VT, 1993), pp. 127-138. This study has been extended in Julian Holland, "Charles Wheatstone and the representation of waves. I,' Rittenhouse 13, 86-106 (1999); "Charles Wheatstone and the representation of waves. II,' Rittenhouse (in press). The most recent biography of Wheatstone is Brian Bowers, Sir Charles Wheatstone FRS 1802-1875 (HMSO, London, 1975). Machines designed to demonstrate wave motion are related to, but not the same as, harmonographs. I have made no attempt to survey the literature of this extensive class of apparatus. However, Barus gives a detailed discussion of a complex apparatus of his design in Carl Barus, "The objective presentation of harmonic motion (with Plate II),' Science, n.s. 9, 385-405 (17 March 1899). All of this must be supplemented by Thomas B. Greenslade, Jr., 'A Apparatus for natural philosophy: 19th century wave machines,' Phys. Teach. 18, 510-517 (1980).

${ }^{7}$ Thomas Sebastian Bazley, Index to the Geometric Chuck (Waterlow and Sons, London, 1875). The author wrote in his introduction: "The impression of this work consists of 150 copies only, probably about equivalent to the number of persons who take an interest in this peculiar branch of amateur mechanism; and as the lithographic stones were obliterated as the successive transfers were completed, the book cannot be reprinted.' (p. v) ${ }^{8}$ Reference 7, pp. 14-15.

${ }^{9}$ Edward C. Pickering, "On the experiment of Lissajous,' J. Franklin Inst. 3rd Ser. 57, 55-58 (January, 1869). A variation on this design was sold much later under the name, "Sinograph", (automatic sine curve tracer), suggested by W. C. Dod and Eugene Albaugh. Scientific Instruments, Laboratory Apparatus and Supplies (Central Scientific Company, Chicago, 1936), p. 1165; Cat. No. 75510, \$40.00. Thomas B. Greenslade, Jr. has kindly provided the following biographical note on Pickering:

-A prominent example [of an important figure in 19th century American science] is Edward Charles Pickering (1846-1919), who spent the last forty two years of his life as the Director of the Harvard Observatory. He prepared for college at the Boston Latin School, and was awarded his S. B. degree from Harvard's Lawrence Scientific School at the age of nineteen. After a year of teaching mathematics at Lawrence Scientific School, he crossed the Charles River in 1866 to join the faculty of the new Massachusetts Institute of Technology, which at that time was on the south side of the river in Boston. For one year he was an assistant instructor of mathematics, and from 1868 to 1877 he was the Thayer professor of physics at M.I.T.

Additional information on Pickering may be found in Howard Plotkin, "'Pickering, Edward Charles,"' Dictionary of Scientific Biography (Scribner's, New York, 1974), Vol. X, pp. 599-601; Bessie Zaban Jones and Lyle Gifford Boyd, The Harvard College Observatory: The First Four Directorships, 1839-1919 (Harvard U.P., Cambridge, 1971).

${ }^{10} \mathrm{~A}$. E. Donkin, "On an instrument for the composition of two harmonic curves,'” Rep. Br. Assoc. Adv. Sci. 43, 45-46 (1873); Donkin noted here that "The instrument is constructed by Messrs. Tisley and Spiller, of Brompton Road, to whom several improvements on the original model are due." A further discussion, with an illustration, is in: A. E. Donkin, "On an instrument for the composition of two harmonic curves,', Proc. R. Soc. London 22, 196-199 (19 February 1874). Tyndall, in his lectures on sound, referred to Donkin's apparatus reported here and noted: "I saw the apparatus as a wooden model, before it quitted the hands of its inventor, and was charmed with its performance. It is now constructed by Messrs. Tisley and Spiller.' John Tyndall, Sound (Appleton, New York and London, 1903), 3rd ed., p. 422. Further discussion may be found in W. F. Donkin, Acoustics (Clarendon, Oxford, 1884), 2nd ed., pp. 50-56. A similar apparatus is described by E. W. Blake, "A machine for drawing compound harmonic curves," Am. J. Otology 1, 81-86 (plus plates) (April, 1879). An abstract was published in Nature (London) 20, 103-105 (29 May 1879). Blake noted that Donkin's apparatus could draw the combination of only two curves; his could draw the combination of three. A biography of W[illiam] F[ishburn] Donkin, who was Savilian professor of astronomy at Oxford, may be found in William Jerome Harrison, "'Donkin, William Fishburn," Dictionary of National Biography (Oxford U.P., London), Vol. V, p. 1125. His son, A[rthur] E[dward] Donkin may be found in Joseph Foster, Alumni Oxonienses (Joseph Foster, London, 1887), Vol. 1, p. 378; I have been unable to find more on him. Following are references to other devices for drawing harmonic curves which appeared in the literature about this period of time. These are brief and, even when illustrated, are not completely clear as to their design or of the curves that they draw: J. C. E. Ellis, "A machine for tracing curves described by points of a vibrating string;,..," Proc. Cambridge Philos. Soc. 2, 256-260 (26 February 1872); John Trowbridge, "Simple apparatus for illustrating periodic motion,', Proc. Am. Acad. Arts Sci. 15, 232-234 (1880); Charles H. Chandler, "An improved harmonograph," Trans. Wisc. Acad. Sci., Arts, Lett. 10, 61-63 (1895); Walter P. White, “Apparatus for drawing harmonic curves,' Sch. Sci. Math. 3, 503-506 (March 1904).

${ }^{11}$ Nature (London) 20, 187 (19 June 1879); an identical report was published in Mon. J. Sci., 3rd ser. 1, 508-509 (July, 1879).

${ }^{12}$ The Oxford English Dictionary (Clarendon, Oxford, 1989), Vol. VI, 2nd ed., p. 1125. The citation is to the Mon. J. Sci. report. As has been noted previously, however, this term had been used to describe a pendulum apparatus developed and advertised by Tisley two years earlier. See Ref. 1, and Ref. 28 therein.

${ }^{13}$ George M. Hopkins, Experimental Science, Elementary Practical and Experimental Physics Vol. II (Munn, New York, 1911), 27th ed., pp. 133136.

${ }^{14}$ Rigge also provided a description of this apparatus based on Hopkins' account. He noted that the cycloidotrope in the physical cabinet at Creighton University had been purchased in 1883 from J. H. Steward, of London, for one pound ten shillings. William F. Rigge, S. J., Harmonic Curves (The Creighton University Press, Omaha, NE, 1926), pp. 74-75.

${ }^{15}$ Reference 13 , pp. 133-135. Kerr also described a similar, but somewhat more elaborate, apparatus called a "geometric pen"' which was also developed by Pumphrey. See Richard Kerr, "The Geometric Pen,', in Jo- 
seph Goold, Charles E. Benham, Richard Kerr, and L. R. Wilberforce, Harmonic Vibrations and Vibration Figures, edited by Herbert C. Newton (Newton \& Co., Scientific Instrument Makers, London, 1909), pp. 184194. It was available for purchase from Newton \& Co. for $£ 1818$ s.

${ }^{16}$ Marc Dechevrens, 'Le campylographe, machine à tracér des courbes,' C. R. Acad. Sci. 130, 1616-1620 (11 June 1900).

${ }^{17}$ Marc Dechevrens, "Vision stéréoscopique des courbes tracées par les appareils phases,' C. R. Acad. Sci. 131, 408-410 (15 August 1900).

${ }^{18}$ Marc Dechevrens, "Le campylographe: Appareil à dessiner des courbes géométriques, des figures stéréoscopiques et des dessins artistiques,' Revue des Questions Scientifiques, 2nd Ser. 19, 21-46 (January, 1901).

${ }^{19}$ L. Reverchon, "Le 'campylographe' du Pere Marc Dechevrens S.J.' La Nature 28, 540-542 (1900).

20 “The campylograph,' Sci. Am. Suppl 50, 20874 (15 December 1900).

${ }^{21}$ Reference 14, p. 78.

${ }^{22}$ Reference 19, p. 540; Ref. 20, p. 20874. A much simplified apparatus, but one very similar to Dechevrens', was described by O. Herrera, 'Mechanical device to draw Lissajous figures,' Phys. Teach. 29, 284-285 (1991). Only one pulley is adjustable, and it must be replaced for each change in the angular speed of the system. The pulleys are connected by means of strings.

${ }^{23}$ Reference 14 , pp. 79-81. Rigge's account of the campylograph is based on his correspondence with Dechevrens. He noted that he had not had access to the articles cited above, even though he had heard of them. Dechevrens was known principally as a meteorologist and as an authority on the theory of cyclones, for which he is still cited. See: Gisela Kutzbach, The Thermal Theory of Cyclones: A History of Meteorological Thought in the Nineteenth Century (American Meteorological Society, Boston, 1979), pp. 137-138; the National Union Catalog Pre-1965 Imprints (Mansell, Chicago, 1973), Vol. 136, p. 247 provides a suggestive list of his work. He was born 26 July 1845 and died 6 December 1923; he had worked at the St. Louis Observatory in Jersey, Channel Islands from 1887 until his death. A brief biography may be found in J. de Moidrey, S. J., "Biographical sketch of Marc Deschevrens [sic], S. J.,', Terr. Magn. Atmos. Electr. 30, 147 (1925).

${ }^{24}$ Robert E. Moritz, "The cyclo-harmonograph: An instrument for drawing large classes of important higher plane curves," Sci. Am. Suppl. 82, 84-85 (5 August 1916).

${ }^{25}$ Robert E. Moritz, "On the construction of certain curves given in polar coordinates,', Am. Math. Monthly 24, 213-220 (May, 1917). The figure is from p. 216.

${ }^{26}$ Reference 25 , p. 216.

${ }^{27}$ Reference 25, p. 217.

${ }^{28}$ Reference 24 , p. 84 . More detailed drawings of the construction of the apparatus are given here.

${ }^{29}$ Reference 25 , p. 217 . Moritz also wrote an extensive mathematical study of this class of curves in Robert W. Moritz, Cyclic-Harmonic Curves: A Study in Polar Coordinates (University of Washington Press, Seattle, WA, 1923). A brief biographical sketch is available in Who Was Who in America (A. N. Marquis, Chicago, 1943), Vol. 1, p. 866.

${ }^{30}$ A. C. Banfield, "The photo-ratiograph: A new instrument for the study of vibrations,' Sci. Am. Monthly 3, 44-45 (January, 1921). It is noted that this article is of the "Courtesy of London Illustrated News," which I have not seen. A short summary was published in "Novel instrument records vibrations,' Illustrated World 35, 453 (May, 1921).

${ }^{31}$ Reference 30, p. 45.

${ }^{32}$ L. Pearce Williams, ed., Album of Science: The Nineteenth Century (Scribners, New York, 1978), p. 10.

${ }^{33}$ A. Frederick Collins, Experimental Mechanics (D. Appleton, New York and London, 1931), pp. 71-74. The author noted that the "Wondergraph", had previously been sold by the E. J. Horsman Company of New York; however, it was no longer available at the time of his writing.

${ }^{34}$ C. L. Stong, "The amateur scientist," Sci. Am. 212, 128-129 (May, 1965).

${ }^{35}$ A. D. Bulman, Models for Experiments in Physics (Crowell, New York, 1966), pp. 12-31.

${ }^{36}$ M. J. Hoferer, S. J. "The kukulograph,' Sci. Am. 148, 31 (January, 1933).

${ }^{37}$ Kenner Products Co., Cincinnati, OH, copyright, 1967. The versions on the current market are copyright by Hasbro, Inc., Pawtucket, RI. All references here are to the first design, which has greater versatility for the purposes described. A later version came with a curved triangular wheel for tracing different curves. General Mills Fun Group, Inc., Cincinnati, OH, copyright, 1972. This wheel is known as a "Reuleaux triangle." Its properties have recently been described in James A. Flaten, "Curves of constant width,', Phys. Teach. 37, 418-419 (1999). I have not examined the curves which may be drawn with this. The earlier versions came with pins to fasten the wheels to cardboard, which, in the wisdom of hindsight, are not now considered appropriate for young children to use. The later versions do not use pins. The term, 'Spirograph,', was introduced in an entirely different context in 1890. It was: "An instrument which provides a continuous tracing of the movements of the lungs during respiration.", The Oxford English Dictionary (Clarendon, Oxford, 1989), Vol. XVI, 2nd ed., p. 262.

${ }^{38}$ Robert J. Whitaker, ' Mathematics of the Spirograph,' Sch. Sci. Math. 88, 554-564 (1988).

${ }^{39}$ The Project Physics Course: Teacher Resource Book (Holt, Rinehart and Winston, New York, Toronto, 1971), pp. 143-147. This apparatus was reviewed by Margaret Foster, "Turntable oscillators-An evaluation," Phys. Teach. 9, 55-58 (1971), with responses from the manufacturers.

${ }^{40}$ Ernst Mach, "Uber eine Vorrichtung zur mechanisch-graphischen Darstellung der Schwingungscurven,' Ann. Phys. Chem. 129, 464-466 (1866). Mach referred to Wheatstone's kaleidophone and noted that it was produced by König.

${ }^{41}$ Joseph Frick, Dr. J. Fricks Physikalische Technik;..., Zweiter Band, Zweite Abteilung (Friedrich Bieweg und Sohn, Braunschweig, 1909), 7th ed., pp. 1703-1708.

${ }^{42}$ Dayton Clarence Miller, The Science of Musical Sounds (Macmillan, New York, 1926), 2nd ed., pp. 6-12.

${ }^{43}$ The figure of Stöhrer's apparatus, reproduced as Fig. 10, comes from Adolf F. Weinhold, Physikalische Demonstrationen (von Quandt \& Händel, Leipzig, 1905), p. 296; extensive discussion of its operation is on pp. 295-298. See, also, Thomas B. Greenslade, Jr., Ref. 6, particularly pp. 516-517. Additional discussion may be found in Joseph Frick, Dr. J. Fricks Physikalische Technik;..., Erster Band, Zweite Abteilung (Friedrich Bieweg und Sohn, Braunschweig, 1905), 7th ed., p. 1325. Frick also included examples of several other curve drawing devices, pp. 1324-1326.

${ }^{44}$ Reference must be made, however, to A. B. Kempe, How to Draw a Straight Line: A Lecture on Linkages (Macmillan, London, 1877; reprinted, National Council of Teachers of Mathematics, Reston, VA, 1977). A study of linkages is important in many aspects of machine design. In the present context see, for example, Robert R. Reid and Du Ray E. Stromback, "Mechanical Computing Mechanisms," in Mechanisms, Linkages, and Mechanical Controls, edited by Nicholas P. Chironis (McGraw-Hill, New York, 1965), pp. 120-137. A recent textbook related to the subject is Homer D. Eckhardt, Kinematic Design of Machines and Mechanisms (McGraw-Hill, New York, 1998).

${ }^{45}$ Reference 14 , p. 81.

${ }^{46}$ William F. Rigge, “A compound harmonic motion machine. I,' Sci. Am. Suppl. 85, 88-91 (9 February 1918); "A compound harmonic motion machine. II,' 85, 108-110 (27 September 1919); H. Volta, “Une machine a tracer les courbes," La Nature 46, 196-199 (27 September 1919). The completed machine is described in Ref. 14, pp. 81-91. The majority of Rigge's book discusses the mathematics of the various curves that can be drawn with the machine and provides examples of these. Brief biographies of Rigge (9 September 1857-31 March 1927) may be found in Rev. James McCabe, S. J., ' 'William F. Rigge,' Pop. Astr. 35, 247-249 (May, 1927), and in Francis A. Tondorf, "Rigge, William Francis," Dictionary of American Biography (Scribner's, New York, 1935), Vol. XV, pp. 601602. From 1896 until his death he was director of the Creighton University Observatory. In addition he taught physics and mathematics. For most of his professional life he contributed extensively to professional and popular journals, writing on astronomy, physics, mathematics, and the history of astronomy. This writer is currently compiling a bibliography of his writings and intends to write a more detailed account of his machine, based on actual examination of it.

${ }^{47}$ Reference 14, pp. 87-91.

48، 'Obituary: Professor Blackburn,' The Times (London), 12 October 1909.

${ }^{49}$ Reference 14 , pp. 91-93.

${ }^{50}$ Reference 14 , p. 11.

${ }^{51}$ Reference 14 , pp. 122-132.

${ }^{52}$ H. Martyn Cundy and A. P. Rollett, Mathematical Models (Clarendon, Oxford, 1961), 2nd ed., p. 244.

${ }^{53}$ Thomas B. Greenslade, Jr., "'19th Century textbook illustrations. XXVII. Harmonographs,' Phys. Teach. 17, 256-258 (1979); “'19th Century textbook illustrations-LI: The kaleidophone,', ibid. 30, 38-39 (1992); “All about Lissajous figures," 31, 364-370 (1993); "The double-elliptic harmonograph,', 36, 90-91 (1998). 
${ }^{54}$ S. Tolansky, "Complex curvilinear designs from pendulums," Leonardo 2, 267-274 (1969).

${ }^{55}$ While dated, Ronald Pearsall, Collecting and Restoring Scientific Instruments (Arco, New York, 1974) is useful. The author provides an extensive glossary of the names of different instruments; strangely, no form of harmonograph is among them. This should be supplemented by Gerard L'E. Turner, Antique Scientific Instruments (Blandford, Poole, Dorset, UK, 1980); Nineteenth-Century Scientific Instruments (Southby Publications, University of California Press, Berkeley, 1983). Both are illustrated with a number of colored plates of apparatus.

${ }^{56}$ J. Dennis Lawrence, A Catalog of Special Plane Curves (Dover, New York, 1972), p. 65.

${ }^{57}$ E. H. Lockwood, A Book of Curves (Cambridge U.P., Cambridge, 1967), pp. 139-140.

${ }^{58}$ Reference 57, pp. $146-148$.

${ }^{59}$ Reference 57, pp. 139-140. The distinction between "epitrochoids" and "epicycloids" and between "hypotrochoids" and "hypocycloids" is not consistent among all authors. Proctor emphasizes the distinction (Ref. 4, pp. 92-134); as does Rigge, who follows Proctor (Ref. 14, pp. 94-121). As noted above, Lawrence and Lockwood make the distinction. Sharp, in his useful discussion of these curves encountered in the gears of a bicycle, makes the same distinction. Archibald Sharp, Bicycles \& Tricycles: An Elementary Treatise on Their Design and Construction (Longmans, Green, New York, 1896; MIT Press Paperback, Cambridge, MA, 1979), p. 27. However, neither Pedoe nor Maor mention "trochoids" in their discussion of cycloidal curves: Dan Pedoe, Geometry and the Liberal Arts (St. Martins Press, New York, 1976), pp. 218-241; Eli Maor, Trigonometric Delights (Princeton U.P., Princeton, NJ, 1998), pp. 95-107.

${ }^{60}$ The following is summarized from my discussion in Ref. 38. This was strongly dependent on Proctor, Ref. 4; Rigge, Ref. 14; Lawrence, Ref. 56; and Lockwood, Ref. 57. Since this article was published, the following have appeared which refer to various aspects of the curves produced by the Spirograph: Joseph D. Romano, "Foucault's pendulum as a Spirograph," Phys. Teach. 35, 182-183 (March, 1997); Maor, Ref. 59, pp. 93-107; Dennis Ippolito, "The mathematics of the Spirograph," Math. Teach. 92, 354-358 (April, 1999).

\section{WHEN WILL SCIENCE END?}

A question that is sometimes asked is, When will science end? It may be worth while to devote a little attention to the other question, How can it end? Usually a scientific advance is considered to consist of a surprising new discovery-which means, in terms of the present theory, that some old hypothesis is rejected by a significance test, and possibly that a new one is put in its place. The steady improvement in accuracy due to improved methods of experiment and observation, and to the combination of increasing numbers of observations, is less spectacular, but it also is a genuine advance, and usually plays an important part in the definite changes made in hypotheses. If we should ever reach a stage where all laws were known, science need not end; for the relevant parameters could be determined with ever-increasing accuracy by increasing the numbers of observations. The conclusion seems to be, therefore, that science cannot end. It must always either discover new laws or increase the accuracy of the estimates of the parameters in the old ones. Human interest might fail, however, if the new laws were not such as to arouse it; or if the accuracy already obtained was as great as was needed. A stage might be reached, for instance, when all advances consisted of the discovery of internal correlations between observational errors. As a rule such correlations decrease the more widely separated the observations are, and the uncertainty of an estimate from a mean will diminish, though less rapidly than $n^{-1 / 2}$. But for the same reason the uncertainty of a prediction to $n$ observations will diminish less rapidly than $n^{-1 / 2}$ and there will be less need for increase of accuracy in the estimates used to make it. I think, therefore, that it is impossible for science to end, but it is possible for it to become uninteresting. But that will not be for some time yet.

Harold Jeffreys, Theory of Probability (Clarendon Press, Oxford, 1939), p. 355. 